- Original Article

\title{
The Effects of Weight Control Behaviors among Korean Obese Adults
}

\author{
Li-Ly Kang, Ha-Nui Kim, Young-Ah Jung, Hwan-Sik Hwang*, Hoon-Ki Park, Kye-Yeung Park \\ Department of Family Medicine, Hanyang University Medical Center, Seoul, Korea
}

Background: This study aimed to identify and examine the effects of weight control behaviors correlated with weight loss in obese individuals who attempted to lose weight within the past year.

Methods: In this cross-sectional study, data from 9,461 obese individuals were collected from the fifth and sixth Korean National Health and Nutrition Examination Survey (2010-2014). Three of nine verified methods of weight control suggested in the survey were selected: diet therapy (reduced food intake), exercise therapy (exercise), and medication therapy (prescribed weight loss medications). Participants were divided into one of seven groups (diet therapy alone; exercise therapy alone; drug therapy alone; combined diet and exercise therapy; combined exercise and drug therapy; combined diet and drug therapy; or combined diet, exercise, and drug therapy). Logistic regression analysis was used to determine whether the group that tried to lose weight in the past year had indeed lost weight compared to the group that did not.

Results: The odds ratios for weight loss ( $\geq 3$ but $<6 \mathrm{~kg}$ vs. $\geq 6$ but $<10 \mathrm{~kg}$ ) for the combined therapies were 2.05 (95\% confidence interval, 1.23-3.41) for combined diet and exercise therapy and 5.43 (1.74-16.92) for combined diet, exercise, and drug therapy.

Conclusion: All levels of weight loss were significantly associated with combined diet and exercise therapy. Weight loss $\geq 6 \mathrm{~kg}$ but $<10 \mathrm{~kg}$ was significantly associated with combined diet and exercise therapy as well as with combined diet, exercise, and medication therapy among individuals who tried to lose weight in the past year:

Keywords: Weight Loss; Obesity; Diet Therapy; Exercise Therapy; Drug Therapy

Received: February 24, 2017, Revised: June 19, 2017, Accepted: July 11, 2017

*Corresponding Author: Hwan-Sik Hwang https://orcid.org/0000-0002-6248-7411

Tel: +82-2-2290-8738, Fax:+82-2-2281-7279, E-mail: fmhwang@hanyang.ac.kr 


\section{INTRODUCTION}

Obesity is a risk factor for numerous chronic diseases, including diabetes mellitus (DM), stroke, myocardial infarction, and cancer. ${ }^{1,2)}$ Its prevalence among Korean adults has been steadily increasing, from $26.9 \%$ in 2001 to $32.8 \%$ in 2014 . $^{2,3)}$ The socioeconomic cost of obesity and overweight people in Korea has reached 1.8 trillion Korean won. ${ }^{4}$ This is not only an issue in Korea; according to a nationally representative survey of adults in the United States, the prevalence of obesity in 2013-2014 was $35.0 \%$ in men and $40.4 \%$ in women. ${ }^{1)}$

The 2013 Guidelines for the Management of Overweight and Obesity in Adults published by the American College of Cardiology states that restricted calorie intake and regular exercise should be combined to induce weight loss. ${ }^{4)}$ Pharmacotherapy should be used only as part of a program that includes diet, physical activity, and behavior therapy. ${ }^{3)}$ Although expert help is essential for effective weight loss, ${ }^{5)}$ in many cases, people pursue various unhealthy weight loss methods, including dietary restriction alone, to achieve simpler and faster weight loss. ${ }^{6}$ Although dietary therapy is effective at reducing weight loss, there is a downside to lowering one's resting metabolic rate. ${ }^{7)}$ Weight losses as little as $3 \%-5 \%$ of one's body weight can lead to clinically meaningful reductions in cardiovascular risk factors and DM risk, weight loss of $5 \%-10 \%$ is the standard goal. ${ }^{3,8)}$

We designed this cross-sectional study to compare the effect of single and combination weight loss methods in obese individuals. Also, we investigated which weight control behaviors led to more effective weight loss in obese patients who tried to lose weight in the past year, using the raw data from the fifth and sixth Korean National Health and Nutrition Examination Survey (KNHANES).

\section{METHODS}

\section{Participants}

We used raw data from the fifth and sixth KNHANES, which was conducted from January 2010 to December 2014. The sample regions for the KNHANES (survey districts) were extracted via a complex stratified multistage probability cluster sampling method to enhance sample representability and estimation accuracy. The KNHANES is a nationally representative cross-sectional survey conducted by the Korean Ministry of Health and Welfare and the Korea Centers for Disease Control and Prevention (KCDC). Individuals participating in the KNHANES completed a questionnaire consisting of a health interview survey, health behavior survey, nutrition survey, and health examination survey. Among non-pregnant individuals aged $\geq 19$ years who participated in the KNHANES, 9,461 individuals with a body mass in$\operatorname{dex}(\mathrm{BMI}) \geq 25.0 \mathrm{~kg} / \mathrm{m}^{2}$ were enrolled in this study. Written informed consent was given by all participants and the protocols for the KNHANES V and VI were approved by the Institutional Review Board of the KCDC (2010-02CON-21-C, 2011-02CON-06-C, 2012-01EXP-012C, 2013-07CON-03-4C, and 2013-12EXP-03-5C). The current study did not require additional institutional review board approval because the KNHANES data set is publicly available.

\section{Demographics}

Information was collected about participant age, sex, average income, alcohol consumption, smoking status, total energy intake, and anthropometric measurements. BMI was calculated by dividing weight $(\mathrm{kg})$ by height squared $\left(\mathrm{m}^{2}\right)$. The cutoff value for obesity was a BMI $\geq 25 \mathrm{~kg} /$ $\mathrm{m}^{2}$ based on the Asian-Pacific obesity diagnostic criteria.

Weight loss and weight control methods used in the past year were measured using the health survey items suggested in the KNHANES. The respondents answered the question "Have you willingly attempted to control your weight in the past year?" by selecting one of the following choices: "I have tried to lose weight," "I have tried to maintain my weight," "I have tried to gain weight," and "I have not tried to control my weight." Those who answered "I have tried to lose weight" were classified into the weight loss attempt group. The respondents also answered the question "Mark all of the methods that you have used to lose or maintain weight in the past year" by marking their methods of choice from nine options (exercise, fasting, reduced food intake, skipping a meal, over-the-counter diet pills, prescribed weight loss medications, herbal medicine, functional food, one-food diet, and other). For the analysis, three verified items were selected: diet therapy (reduced food intake), exercise therapy (exercise), and medication therapy (prescribed weight loss medications).

The participants were further divided into one of the following seven groups: diet therapy alone; exercise therapy alone; medication therapy alone; combined diet and exercise therapy; combined exercise and medication therapy; combined diet and medication therapy; or combined diet, exercise, and medication therapy. We defined weight loss group who answered "yes" to the questionnaire "I lost at least $3 \mathrm{~kg}$ but less than $6 \mathrm{~kg}$ in the prior year" and "I lost at least $6 \mathrm{~kg}$ but less than 10 $\mathrm{kg}$ in the prior year" and "I lost more than $10 \mathrm{~kg}$ in the prior year." The others were considered the weight loss failure group. The participants were further divided into one of the following three groups: weight loss $\geq 3 \mathrm{~kg}$ but $<6 \mathrm{~kg}$, weight loss $\geq 6 \mathrm{~kg}$ but $<10 \mathrm{~kg}$, and weight loss $\geq 10 \mathrm{~kg}$.

\section{Statistical Analysis}

The KNAHNES raw data were analyzed per the guidelines using IBM SPSS ver. 21.0 (IBM Corp., Armonk, NY, USA) software. Nominal variables were analyzed using the chi-square test. Data are presented as mean \pm standard error. The weight loss amounts of the seven types of weight control methods were verified using a complex sample logistic regression after the adjustment for age, sex, economic status, weight, BMI, waist circumference, drinking, smoking, and total energy intake. Significance level was set at $\mathrm{P}<0.05$.

\section{RESULTS}

Our sample $(n=9,461)$ comprised obese individuals, of whom 7,023 claimed to have tried to lose weight in the past year, while 2,438 did not. The participants' baseline characteristics according to weight con- 
trol method are shown in Table 1 . The mean age was the lowest in the combined diet, exercise, and medication therapy group (37.75 \pm 1.39 years) and the highest in the combined diet and medication therapy group (50.41 \pm 1.33 years). There was a higher proportion of men in the exercise therapy alone group and a higher proportion of women in the drug therapy alone group. Body weight was the highest in the combined diet, exercise, and medication therapy group $(78.37 \pm 1.19 \mathrm{~kg})$ and lowest in the combined diet and medication therapy group $(71.12 \pm 1.05 \mathrm{~kg})$. BMI was the highest in in the combined diet, exercise, and medication therapy group $\left(29.51 \pm 0.30 \mathrm{~kg} / \mathrm{m}^{2}\right)$ and lowest in the exercise only group $\left(27.44 \pm 0.05 \mathrm{~kg} / \mathrm{m}^{2}\right)$. Waist circumference was the highest in the combined diet, exercise, and medication therapy group $(91.89 \pm 0.89 \mathrm{~cm})$ and lowest in the combined diet and medication therapy group $(89.20 \pm 1.24 \mathrm{~cm})$. Daily calorie intake was the lowest in the drug therapy alone group $(1,670 \pm 103.0 \mathrm{kcal})$ and highest in the exercise therapy alone group $(2,275 \pm 31.26 \mathrm{kcal})$ (Table 1$)$.

We sought to examine whether weight control method was correlated with weight loss in the group of individuals who tried to lose weight in the past year compared to those who did not (Table 2). Our results indicated that all levels of weight loss were significantly associated with combined diet and exercise therapy among individuals who tried to lose weight in the past year. Weight loss in the $\geq 3 \mathrm{~kg}$ but $<6 \mathrm{~kg}$ group was significantly associated with diet therapy alone as well as with exercise therapy alone and combined diet and exercise therapy. Weight loss in the $\geq 6 \mathrm{~kg}$ but $<10 \mathrm{~kg}$ group was significantly associated with exercise therapy alone as well as with combined diet and exercise therapy and combined diet, exercise, and medication therapy. Weight loss in the $\geq 10 \mathrm{~kg}$ group was significantly associated with combined diet and exercise therapy $(\mathrm{P}<0.05)$.

We performed a logistic regression to examine the correlations be- tween the seven weight loss methods and weight loss and found that diet therapy alone, exercise therapy alone, and combined diet and exercise therapy were significantly correlated with $\geq 3 \mathrm{~kg}$ but $<6 \mathrm{~kg}$ weight loss. Combined diet and exercise therapy and combined diet, exercise, and medication therapy were significantly correlated with $\geq 6 \mathrm{~kg}$ but $<10 \mathrm{~kg}$ weight loss. Only combined diet and exercise therapy was significantly correlated with $\geq 10 \mathrm{~kg}$ weight loss (Table 3 ).

Furthermore, combined diet, exercise, and medication therapy was more significantly correlated with $\geq 6 \mathrm{~kg}$ but $<10 \mathrm{~kg}$ weight loss than was combined diet and exercise therapy (odds ratio [OR], 2.05; 95\% confidence interval [CI], 1.23-3.41 for combined diet and exercise therapy; OR, 5.43; 95\% CI, 1.74-16.92 for combined diet, exercise, and medication therapy) (Table 3).

\section{DISCUSSION}

According to the national survey data used in this study, $70.1 \%$ of the entire adult obese population claimed to have tried to lose weight in the past year. Our study results were as follows: (1) diet therapy alone, exercise therapy alone, and combined diet and exercise therapy were significantly correlated with $\geq 3 \mathrm{~kg}$ but $<6 \mathrm{~kg}$ weight loss; (2) combined diet and exercise therapy and combined diet, exercise, and medication therapy were significantly correlated with $\geq 6 \mathrm{~kg}$ but $<10 \mathrm{~kg}$ weight loss; (3) only combined diet and exercise therapy was significantly correlated with $\geq 10 \mathrm{~kg}$ weight loss; (4) combined diet, exercise, and medication therapy was more significantly correlated with $\geq 6 \mathrm{~kg}$ but $<10 \mathrm{~kg}$ weight loss than combined diet and exercise therapy; and (5) the greatest number of people used exercise therapy alone $(n=2,347)$, while the least number of people used combined diet and medication therapy $(n=31)$.

Table 1. Baseline characteristics of the 6,216 study participants by weight loss method

\begin{tabular}{|c|c|c|c|c|c|c|c|}
\hline Characteristic & $\begin{array}{c}\text { Diet } \\
(\mathrm{n}=1,389)\end{array}$ & $\begin{array}{l}\text { Exercise } \\
(n=2,347)\end{array}$ & $\begin{array}{c}\text { Medication } \\
(\mathrm{n}=36)\end{array}$ & $\begin{array}{l}\text { Diet and exercise } \\
\quad(n=2,286)\end{array}$ & $\begin{array}{c}\text { Exercise and } \\
\text { medication }(n=43)\end{array}$ & $\begin{array}{c}\text { Diet and } \\
\text { medication ( } n=31)\end{array}$ & $\begin{array}{l}\text { Diet, exercise, and } \\
\text { medication }(n=84)\end{array}$ \\
\hline Age (y) & $48.47 \pm 0.47$ & $46.78 \pm 0.35$ & $40.71 \pm 2.03$ & $44.13 \pm 0.43$ & $41.56 \pm 0.89$ & $50.41 \pm 1.33$ & $37.75 \pm 1.39$ \\
\hline \multicolumn{8}{|l|}{ Sex } \\
\hline Male & $494(45.2)$ & $1,450(69.1)$ & $2(8.9)$ & $1,221(55.5)$ & $1(0.4)$ & $1(3.4)$ & $11(18.5)$ \\
\hline Female & $895(54.8)$ & 897 (30.9) & $34(91.1)$ & $1,065(45.5)$ & 42 (99.6) & $30(96.6)$ & 73 (81.5) \\
\hline \multicolumn{8}{|l|}{ Income } \\
\hline Low & $278(15.8)$ & $346(11.5)$ & $3(13.5)$ & $385(14.9)$ & $2(3.9)$ & $5(18.4)$ & $5(4.7)$ \\
\hline Middle & $809(60.8)$ & $1,284(57.0)$ & $21(63.7)$ & $1,231(55.9)$ & $29(69.7)$ & $16(55.6)$ & $49(55.6)$ \\
\hline High & $288(23.4)$ & 701 (31.5) & $12(22.7)$ & $656(29.2)$ & $12(26.3)$ & $10(26.0)$ & $30(39.7)$ \\
\hline Weight (kg) & $73.64 \pm 0.36$ & $76.12 \pm 0.29$ & $72.33 \pm 3.67$ & $76.32 \pm 0.33$ & $73.27 \pm 1.09$ & $71.12 \pm 1.05$ & $78.37 \pm 1.19$ \\
\hline Body mass index $\left(\mathrm{kg} / \mathrm{m}^{2}\right)$ & $27.71 \pm 0.08$ & $27.44 \pm 0.05$ & $28.59 \pm 0.69$ & $27.81 \pm 0.07$ & $29.16 \pm 0.50$ & $27.84 \pm 0.25$ & $29.51 \pm 0.30$ \\
\hline Waist circumference (cm) & $90.39 \pm 0.25$ & $90.42 \pm 0.18$ & $89.75 \pm 2.00$ & $90.33 \pm 0.22$ & $90.80 \pm 1.32$ & $89.20 \pm 1.24$ & $91.89 \pm 0.89$ \\
\hline \multicolumn{8}{|l|}{ Alcohol intake } \\
\hline Non-drinker & $225(11.8)$ & $265(8.9)$ & $0(0)$ & $286(9.7)$ & $2(5.3)$ & $6(20.9)$ & $5(7.7)$ \\
\hline Drinker & $1,164(88.2)$ & $2,082(91.1)$ & $36(100)$ & $2,000(90.3)$ & $41(94.7)$ & $25(79.1)$ & 79 (92.3) \\
\hline \multicolumn{8}{|l|}{ Smoking } \\
\hline Never & $917(58.1)$ & $1,103(41.9)$ & $28(74.0)$ & $1,345(52.8)$ & 35 (84.2) & $25(70.4)$ & $60(67.9)$ \\
\hline Former or current & $469(41.9)$ & $1,243(58.1)$ & $8(26.0)$ & $941(47.2)$ & $8(15.8)$ & $6(29.6)$ & $24(32.1)$ \\
\hline Energy intake (kcal/d) & $1,975 \pm 33.79$ & $2,275 \pm 31.26$ & $1,670 \pm 103.0$ & $2,077 \pm 29.11$ & $1,905 \pm 161.54$ & $1,764 \pm 154.75$ & $1,970 \pm 134.52$ \\
\hline
\end{tabular}

Values are presented as mean \pm aluedard error or number (\%). 
Table 2. Weight changes by weight loss method

\begin{tabular}{|c|c|c|c|c|c|c|c|c|c|}
\hline \multirow[b]{2}{*}{ Variable } & \multicolumn{9}{|c|}{ Weight change } \\
\hline & $\begin{array}{c}\text { Weight loss } \\
\geq 3 \mathrm{~kg} \text { but }<6 \mathrm{~kg}\end{array}$ & $\begin{array}{l}\text { Weight loss } \\
\text { failure }\end{array}$ & P-value ${ }^{*}$ & $\begin{array}{c}\text { Weight loss } \\
\geq 6 \mathrm{~kg} \text { but }<10 \mathrm{~kg}\end{array}$ & $\begin{array}{l}\text { Weight loss } \\
\text { failure }\end{array}$ & P-value ${ }^{*}$ & $\begin{array}{l}\text { Weight loss } \\
\geq 10 \mathrm{~kg}\end{array}$ & $\begin{array}{l}\text { Weight loss } \\
\text { failure }\end{array}$ & P-value ${ }^{*}$ \\
\hline Diet & & & 0.00 & & & 0.17 & & & 0.51 \\
\hline Yes & $130(12.8)$ & $969(87.2)$ & & $26(2.4)$ & $1,073(97.6)$ & & $15(0.9)$ & $1,866(99.1)$ & \\
\hline No & $226(6.2)$ & 3,283 (93.8) & & $53(1.6)$ & 3,456 (98.4) & & $27(0.7)$ & 3,482 (99.3) & \\
\hline Exercise & & & 0.00 & & & 0.02 & & & 0.36 \\
\hline Yes & $188(9.7)$ & 1,693 (90.3) & & $43(3.0)$ & $1,838(97.0)$ & & $8(1.1)$ & 1,091 (98.9) & \\
\hline No & $226(6.2)$ & $3,283(93.8)$ & & $53(1.6)$ & $3,456(98.4)$ & & $27(0.7)$ & $3,482(99.3)$ & \\
\hline Medication & & & 0.15 & & & 0.59 & & & 0.63 \\
\hline Yes & $4(13.9)$ & $28(86.1)$ & & 0 & $32(100.0)$ & & 0 & $32(100.0)$ & \\
\hline No & $226(6.2)$ & $3,283(93.8)$ & & $53(1.6)$ & 3,456 (98.4) & & $27(0.7)$ & $3,482(99.3)$ & \\
\hline Diet and exercise & & & 0.00 & & & 0.00 & & & 0.00 \\
\hline Yes & $250(11.1)$ & $1,824(88.9)$ & & $68(3.7)$ & 2,006 (96.3) & & $36(2.3)$ & 2,038 (97.7) & \\
\hline No & 226 (6.2) & $3,283(93.8)$ & & $53(1.6)$ & 3,456 (98.4) & & $27(0.7)$ & $3,482(99.3)$ & \\
\hline Exercise and medication & & & 0.22 & & & 0.06 & & & 0.68 \\
\hline Yes & $5(12.0)$ & $38(88.0)$ & & $2(5.8)$ & $41(94.2)$ & & $1(1.1)$ & $42(98.9)$ & \\
\hline No & $226(6.2)$ & 3,283 (93.8) & & $53(1.6)$ & 3,456 (98.4) & & $27(0.7)$ & $3,482(99.3)$ & \\
\hline Diet and medication & & & 0.43 & & & 0.06 & & & 0.68 \\
\hline Yes & $2(3.5)$ & $29(96.5)$ & & $2(5.8)$ & $29(94.2)$ & & 0 & $31(100.0)$ & \\
\hline No & $226(6.2)$ & 3,283 (93.8) & & $53(1.6)$ & $3,456(98.4)$ & & $27(0.7)$ & $3,482(99.3)$ & \\
\hline Diet, exercise, and medication & & & 0.30 & & & 0.01 & & & 0.46 \\
\hline Yes & $5(3.8)$ & $78(96.2)$ & & $5(5.4)$ & $78(94.6)$ & & 0 & $83(100.0)$ & \\
\hline No & $226(6.2)$ & $3,283(93.8)$ & & $53(1.6)$ & $3,456(98.4)$ & & $27(0.7)$ & 3,482 (99.3) & \\
\hline
\end{tabular}

Values are presented as number (\%).

*By Pearson's chi-square test.

Table 3. Multiple logistic regression estimates associated with weight loss versus weight loss failure by weight loss method*

\begin{tabular}{lccc}
\hline \multicolumn{1}{c}{ Variable } & Weight loss $\geq 3 \mathrm{~kg}$ but $<6 \mathrm{~kg}$ & Weight loss $\geq 6 \mathrm{~kg}$ but $<10 \mathrm{~kg}$ & Weight loss $\geq 10 \mathrm{~kg}$ \\
\hline Diet & $2.40(1.79-3.21)$ & $1.60(0.86-2.98)$ & $2.27(0.74-6.96)$ \\
Exercise & $1.80(1.39-2.34)$ & $1.52(0.86-2.69)$ & $1.50(0.69-3.25)$ \\
Medication & $3.51(0.99-12.45)$ & NA & NA \\
Diet and exercise & $2.21(1.73-2.84)$ & $2.05(1.23-3.41)$ & $2.63(1.44-4.81)$ \\
Exercise and medication & $2.94(0.86-10.07)$ & $2.49(0.30-20.23)$ & $2.64(0.28-24.97)$ \\
Diet and medication & $0.63(0.13-3.07)$ & $4.74(0.99-22.73)$ & NA \\
Diet, exercise, and medication & $0.89(0.29-2.70)$ & $5.43(1.74-16.92)$ & NA
\end{tabular}

Values are presented as odds ratio (95\% confidence interval).

NA, not applicable.

${ }^{*}$ Adjusted for age, sex, income, weight, body mass index, waist circumference, alcohol intake, smoking, and total energy intake.

In our study, single therapy was more popular for weight loss than combination therapy $(n=3,772)$. A single therapy is less likely to be effective since an integration of a variety of treatment methods is essential to treat the multifactorial causes of obesity. ${ }^{3)}$ Greater weight loss produces greater benefits. ${ }^{8)}$ Our findings showed that single therapy was not significantly correlated with greater weight loss ( $\geq 6 \mathrm{~kg}$ but $<10$ $\mathrm{kg}$ ), while triple therapy was more significantly correlated with greater weight loss than was double therapy, suggesting that combining several therapies is more conducive to weight loss.

The 2013 Guidelines for the Management of Overweight and Obesity in Adults and US Preventive Services Task Force recommend combining exercise, diet, and behavioral modification for effective weight loss. Medications may be considered for people whose BMI exceeds $30.0 \mathrm{~kg} / \mathrm{m}^{2}$ or for those who have comorbidities and have a BMI that exceeds $27.0 \mathrm{~kg} / \mathrm{m}^{2}$ if combined diet and exercise therapy does not lead to sufficient weight loss. ${ }^{9,10)}$ In Korea, medication therapy is offered for people with a BMI $\geq 25.0 \mathrm{~kg} / \mathrm{m}^{2}$ or $\geq 23.0 \mathrm{~kg} / \mathrm{m}^{2}$ if an individual has obesity-related complications. ${ }^{11)}$ Our participants comprised obese people (BMI $\geq 25.0 \mathrm{~kg} / \mathrm{m}^{2}$ ). In our study, the group that used drug therapy in addition to diet and exercise demonstrated more effective weight loss than did the group that used only diet and exercise therapy in the $\geq 6 \mathrm{~kg}$ but $<10 \mathrm{~kg}$ weight loss group (OR, 5.43; 95\% CI, 1.74-16.92).

In addition, the group of people who pursued combined diet and exercise therapy per the guidelines was strongly correlated with all levels of weight loss.

Previous studies have suggested that overweight or obese individuals tend to put more effort into losing weight than those who are not 
overweight. ${ }^{12)}$ The proportion of obese people trying to lose weight was $70.1 \%$ in this study, higher than that in the United States. ${ }^{2,12)}$ This is speculated to be the result of a malicious cycle in which individuals reach their target body weight through inappropriate weight loss methods with short-lived effects and a high risk of a yo-yo effect, which ultimately undermines their satisfaction with the chosen method of weight loss and encourages them to resort to inefficient weight loss behaviors again. ${ }^{6}$

Previous studies have noted that many people who try to lose weight do not actually use verified weight loss methods. ${ }^{13,14)}$ One of these verified methods is a combination of dietary control and exercise. ${ }^{12)}$ Studies have documented that reducing total calorie intake and eating a small amount of food over several meals is highly correlated with better diet quality and low $\mathrm{BMI}^{15)}$ and that combining reduced calorie intake with a minimum of 150 minutes of moderate to vigorous physical activity per week is effective for weight loss. ${ }^{13)}$ Furthermore, engaging in group exercise is more effective for long-term weight loss than exercising alone. ${ }^{16)}$ In this study, only one third of people used a combined diet and exercise strategy to lose weight $(n=2,286)$. Similarly, a previous study reported that only one third of people trying to lose weight used diet and exercise therapy, a method confirmed to be effective for weight loss. ${ }^{12)}$

Various weight loss methods are not effective for weight loss in many overweight and obese patients with the exception of a subset of patients who are guided by a physician or expert. ${ }^{17)}$ However, in one study, investigators found that patients who received behavioral interventions had more significant weight loss over a 24-month period than those using self-directed weight loss methods. ${ }^{5)}$ Furthermore, researchers examined the effects of nutrition education and exercise intervention in obese middle-aged women and found a significant postintervention reduction in weight, BMI, and body fat percentage. ${ }^{18)}$ Since the present study could not investigate the effects of physician or expert interventions on weight loss, additional studies are needed to further examine this matter.

The weight loss method people choose is an important factor for losing weight in the short-term and controlling weight loss in the longterm. ${ }^{16)}$ However, the results remain controversial. It has been documented that, among participants on a very low calorie diet, participants of a commercial program, and individuals engaging in self-directed weight loss, only the self-directed group was able to maintain their weight loss over 18 months. ${ }^{19)}$ However, in a 2-year multicenter randomized trial, a commercial program group was able to maintain their weight loss more than a self-directed weight loss group. ${ }^{20)} \mathrm{We}$ could not evaluate the long-term maintenance of weight loss in the current study, so further research is needed.

There are several limitations to this study. First, it was a cross-sectional study using KNHANES data; therefore, we could not draw conclusions regarding causal relationships between weight loss methods and subsequent weight loss. We did not know whether the weight loss effect was caused arbitrarily or for other reasons. Second, variables were measured via self-report questionnaires, which lead to some risk of underestimating certain parameters, such as body weight. Third, in the $\geq 10 \mathrm{~kg}$ weight loss group, the analysis was inadequate due to an insufficient number of cases. Fourth, we had no information about specific weight loss methods (volume of workout, duration, intensity, frequency, and drug types and dose). Fifth, because we selected a group of obese people based on current weight, it is possible that those who succeeded at losing weight and had become normal or overweight over the past year may be missed. Sixth, we divided weight loss according to kilograms. The size of the weight-loss effect varies from person to person, so it is better to divide weight loss according to percent based on weight before weight loss. Seventh, it is difficult to compare the effects of weight loss methods because the target groups are disparate (age, sex, BMI, etc.). Finally, we have concrete knowledge about the duration of the participants' diets or other attempts at weight loss in the past year. Furthermore, patients were instructed to state the method of their weight loss, which makes the responses susceptible to recall bias.

In conclusion, participants on combined diet and exercise therapy and on combined diet, exercise, and drug therapy lost significantly more weight than those who claimed not to have tried to lose weight over the past year.

\section{CONFLICT OF INTEREST}

No potential conflict of interest relevant to this article was reported.

\section{REFERENCES}

1. Flegal KM, Kruszon-Moran D, Carroll MD, Fryar CD, Ogden CL. Trends in obesity among adults in the United States, 2005 to 2014. JAMA 2016;315:2284-91.

2. Kim CS, Ko SH, Kwon HS, Kim NH, Kim JH, Lim S, et al. Prevalence, awareness, and management of obesity in Korea: data from the Korea national health and nutrition examination survey (1998-2011). Diabetes Metab J 2014;38:35-43.

3. Kim MK, Lee WY, Kang JH, Kang JH, Kim BT, Kim SM, et al. 2014 clinical practice guidelines for overweight and obesity in Korea. Endocrinol Metab (Seoul) 2014;29:405-9.

4. Jensen MD, Ryan DH, Apovian CM, Ard JD, Comuzzie AG, Donato KA, et al. $2013 \mathrm{AHA} / \mathrm{ACC} / \mathrm{TOS}$ guideline for the management of overweight and obesity in adults: a report of the American College of Cardiology/American Heart Association Task Force on Practice Guidelines and The Obesity Society. J Am Coll Cardiol 2014;63(25 Pt B):2985-3023.

5. Appel LJ, Clark JM, Yeh HC, Wang NY, Coughlin JW, Daumit G, et al. Comparative effectiveness of weight-loss interventions in clinical practice. N Engl J Med 2011;365:1959-68.

6. Park YR, Cho YG, Kang JH, Park HA, Kim KW, Hur YI, et al. Comparison of obesity and overweight prevalence among Korean adults according to Community Health Survey and Korea National Health and Nutrition Examination Survey. Korean J Obes 2014;23:64-8.

7. Kim KB, Lim KI, So WY, Park SK, Song W. A meta-analysis of the effects of exercise therapy applied in obesity studies. Korean J Obes 
2007;16:177-85.

8. Kushner RF, Ryan DH. Assessment and lifestyle management of patients with obesity: clinical recommendations from systematic reviews. JAMA 2014;312:943-52.

9. Jensen MD, Ryan DH, Donato KA, Apovian CM, Ard JD, Comuzzie AG, et al. Guidelines (2013) for managing overweight and obesity in adults. Obesity 2014;22(S2):S1-S410.

10. Erlandson M, Ivey LC, Seikel K. Update on office-based strategies for the management of obesity. Am Fam Physician 2016;94:361-8.

11. Kim MK. Behavioral intervention and anti-obesity drug therapy. Korean J Med 2013;84:624-8.

12. Kruger J, Galuska DA, Serdula MK, Jones DA. Attempting to lose weight: specific practices among U.S. adults. Am J Prev Med 2004;26:402-6.

13. Serdula MK, Mokdad AH, Williamson DF, Galuska DA, Mendlein JM, Heath GW. Prevalence of attempting weight loss and strategies for controlling weight. JAMA 1999;282:1353-8.

14. Weiss EC, Galuska DA, Khan LK, Serdula MK. Weight-control practices among U.S. adults, 2001-2002. Am J Prev Med 2006;31:18-24.
15. Aljuraiban GS, Chan Q, Oude Griep LM, Brown IJ, Daviglus ML, Stamler J, et al. The impact of eating frequency and time of intake on nutrient quality and body mass index: the INTERMAP Study, a PopulationBased Study. J Acad Nutr Diet 2015;115:528-36.

16. Jakicic JM, Tate DF, Lang W, Davis KK, Polzien K, Neiberg RH, et al. Objective physical activity and weight loss in adults: the step-up randomized clinical trial. Obesity (Silver Spring) 2014;22:2284-92.

17. Yoong SL, Carey ML, Sanson-Fisher RW, D'Este C. A cross-sectional study assessing the self-reported weight loss strategies used by adult Australian general practice patients. BMC Fam Pract 2012;13:48.

18. Kim MS, Choi MS, Kim KN. Effect of nutritional education and exercise intervention on reducing and maintaining weight in obese women. Korean J Community Nutr 2007;12:80-9.

19. Marinilli Pinto A, Gorin AA, Raynor HA, Tate DF, Fava JL, Wing RR. Successful weight-loss maintenance in relation to method of weight loss. Obesity (Silver Spring) 2008;16:2456-61.

20. Heshka S, Anderson JW, Atkinson RL, Greenway FL, Hill JO, Phinney SD, et al. Weight loss with self-help compared with a structured commercial program: a randomized trial. JAMA 2003;289:1792-8. 